\title{
Unusual case of tracheoesophageal fistula caused by impacted denture
}

\author{
Virwar K. Jha, MBBS, and Satinder K. Jain, MS, MCh, FRCSEd, New Delhi, India
}

\author{
From the Department of Cardiothoracic Surgery, Delhi Heart \& Lung Institute, New Delhi, India. \\ Disclosures: Authors have nothing to disclose with regard to commercial support. \\ Received for publication March 15, 2017; revisions received May 24, 2017; accepted for publication June 4, 2017; \\ available ahead of print July 1, 2017. \\ Address for reprints: Dr Satinder K. Jain, MS, MCh, FRCSEd, C-20/A, New Krishna Park, Vikaspuri, New Delhi \\ 110 018, India (E-mail: dr.skjain@yahoo.com). \\ J Thorac Cardiovasc Surg 2017;154:e119-21 \\ $0022-5223 / \$ 36.00$ \\ Copyright (c) 2017 by The American Association for Thoracic Surgery \\ http://dx.doi.org/10.1016/j.jtcvs.2017.06.003
}

- Video clip is available online.

Acquired tracheoesophageal fistula (TEF) caused by foreign body ingestion is a rare entity. Fewer than 12 cases of TEF formation attributable to the ingestion of dental prosthesis has been reported. ${ }^{1}$ The main classic finding of sudden coughing seconds after ingestion of fluids or solids (Ono sign) should arouse suspicion of the diagnosis, ${ }^{2}$ but this may not be present in all the cases.

\section{CASE REPORT}

A 60-year-old woman presented on February 24, 2015, with a diagnosis of acquired TEF as the result of an impacted denture occurring 1 year previously. She had progressive dysphagia, cough on feeding and regurgitation of food, and weight loss. She had an associated history of cough productive of brownish sputum and hemoptysis after 3 failed interventions to retrieve the denture. Two months after ingestion, the patient had a feeding jejunostomy created for nutritional rehabilitation. Physical examination revealed a moderately wasted patient with weight of $45 \mathrm{~kg}$. Systemic examination was within normal limits.

Findings of the chest radiograph were normal. A flexible esophagoscopy and fiberoptic bronchoscopy revealed an impacted denture (Figure 1). High-resolution computed tomography of the chest revealed a fistula between the trachea and esophagus with impacted denture (Figure 2). Tracheal opening of the fistula was $4 \mathrm{~cm}$ proximal to carina, whereas the esophageal opening was approximately $5 \mathrm{~cm}$ from the cricopharyngeus.

After preoperative evaluation, the patient was taken for surgery on February 26, 2015. Under general anesthesia, we were able to dislodge and push the foreign body into the fistulous tract with the beveled lip of a 6-mm Karl Storz rigid bronchoscope (KARL STORZ GmbH \& Co, KG, Tuttlingen, Germany). This facilitated tracheal intubation with a left double-lumen endotracheal tube. Through the right

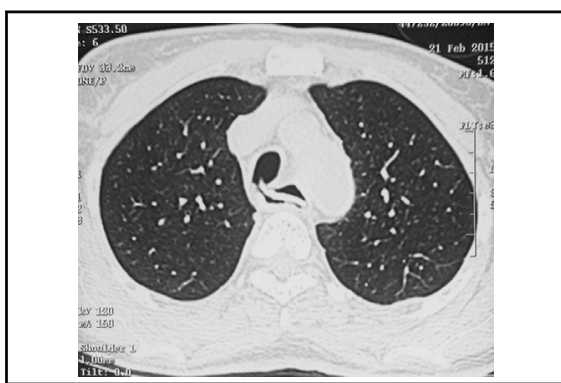

Computed tomography scan showing impacted denture and tracheoesophageal fistula.

Central Message

Acquired tracheoesophageal fistula is a rare clinical entity. Our case is unique in that the impacted denture was removed and tracheoesophageal fistula repaired more than 1 year after its ingestion.

See Editorial Commentary page e123. fourth intercostal space, the posterolateral thoracotomy trachea and esophagus were mobilized along with the TEF (Figure 3). The TEF was $3 \mathrm{~cm}$ long. A badly impacted denture in the esophagus was removed with difficulty after we opened the TEF. An esophageal rent was repaired in 2 layers with 3/0 interrupted Vicryl suture. Margin of tracheal rent freshened and repaired with 3/0 interrupted Vicryl suture. Tracheal repair was reinforced with pleural flap raised from adjacent area with pedicle towards mediastinum and wrapped around trachea isolating it from repaired esophagus. The tracheal repair was tested for air leaks. The patient was extubated in the operating room.

Feeding through jejunostomy tube was resumed on the first postoperative day. Oral normal saline feeding started on the second postoperative day while jejunostomy feeding continued. Fiberoptic bronchoscopy on the fifth postoperative day revealed a healthy tracheal repair. Gastrografin swallow revealed no esophageal leak (Figure 4). The patient gradually progressed to normal diet orally. The patient's feeding jejunostomy tube was removed on the ninth postoperative day. Six month later, the patient remained free from symptoms, on a normal diet, and had gained $7 \mathrm{~kg}$ of weight.

\section{COMMENT}

Impacted swallowed denture may be complicated by the formation of a fistula between the esophagus and trachea at 


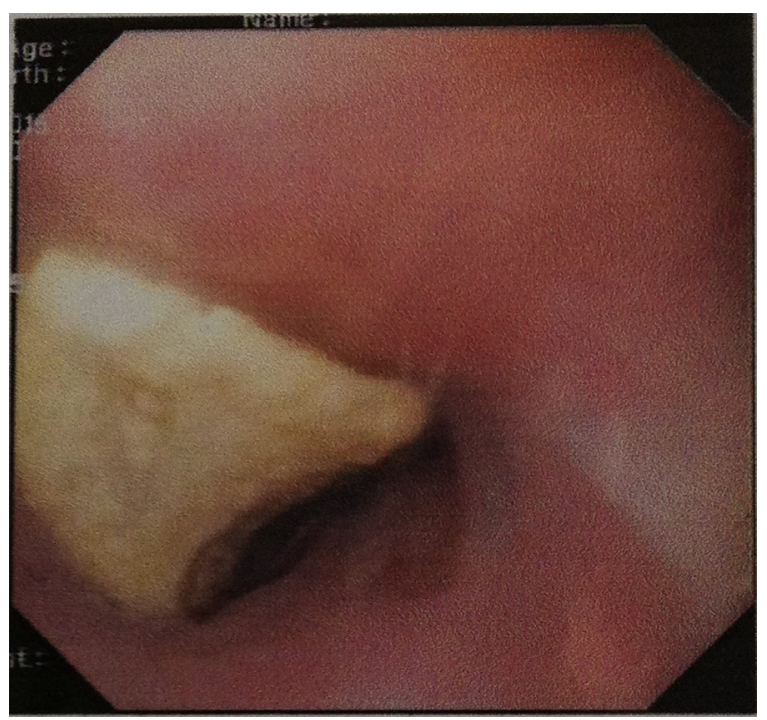

FIGURE 1. Bronchoscopic view of the impacted denture.

different levels when a patient presents with dysphagia, dyspnea, cough on feeding, recurrent pulmonary infection, regurgitation of food, and so on, ${ }^{2,3}$ as happened in this case. In more advanced cases, there can be involvement of recurrent laryngeal nerve or formation of esophago-broncho-aortic fistula. Patients with these complications may present with hoarseness of voice, fatal hematemesis, and hemoptysis. ${ }^{4}$

Duration between onset of symptoms and definitive treatment is an important consideration. As this duration

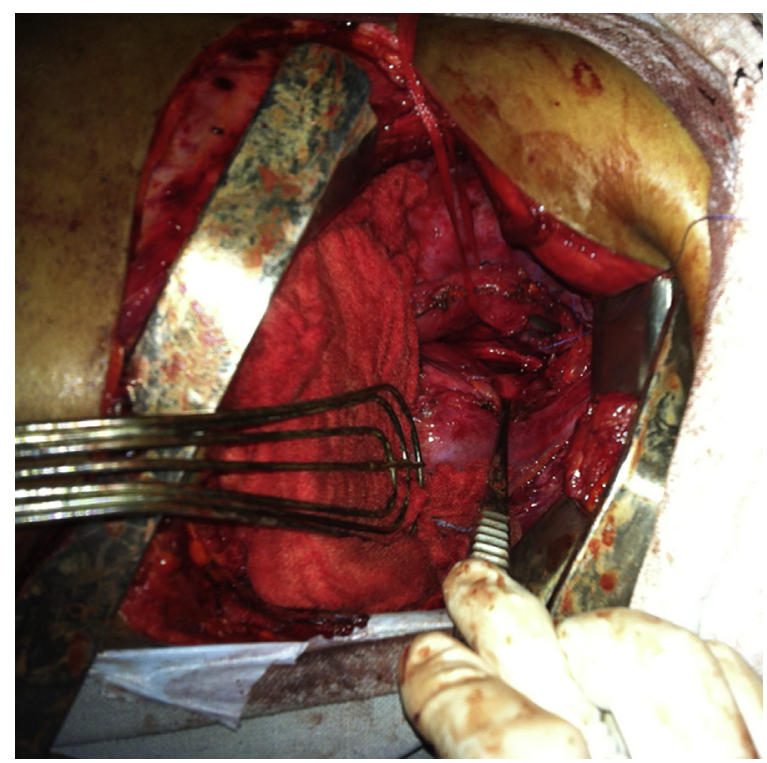

FIGURE 3. Tracheoesophageal fistula: operative view.

increases, the probability and severity of complications increase. This case is probably the first case among reported cases in which duration was as long as 1 year and pathology remained limited to TEF. In previously reported cases, either the patient was treated or the disease had advanced to involvement of adjacent nerve and vessel by the 1-year period.

TEF due to impacted denture is also important from a management point of view because it is a potentially

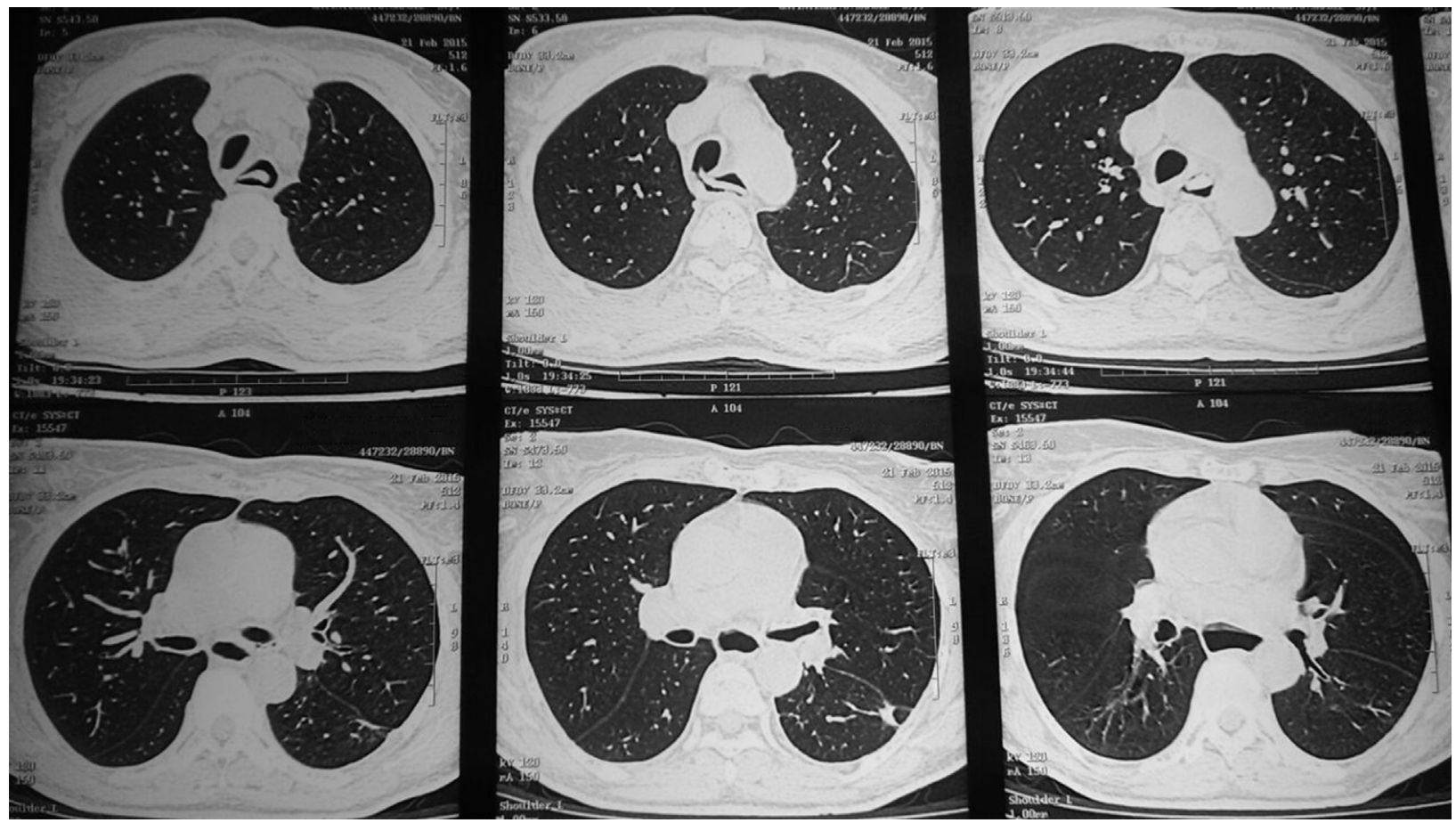

FIGURE 2. Tracheoesophageal fistula and impacted denture: computed tomography. 


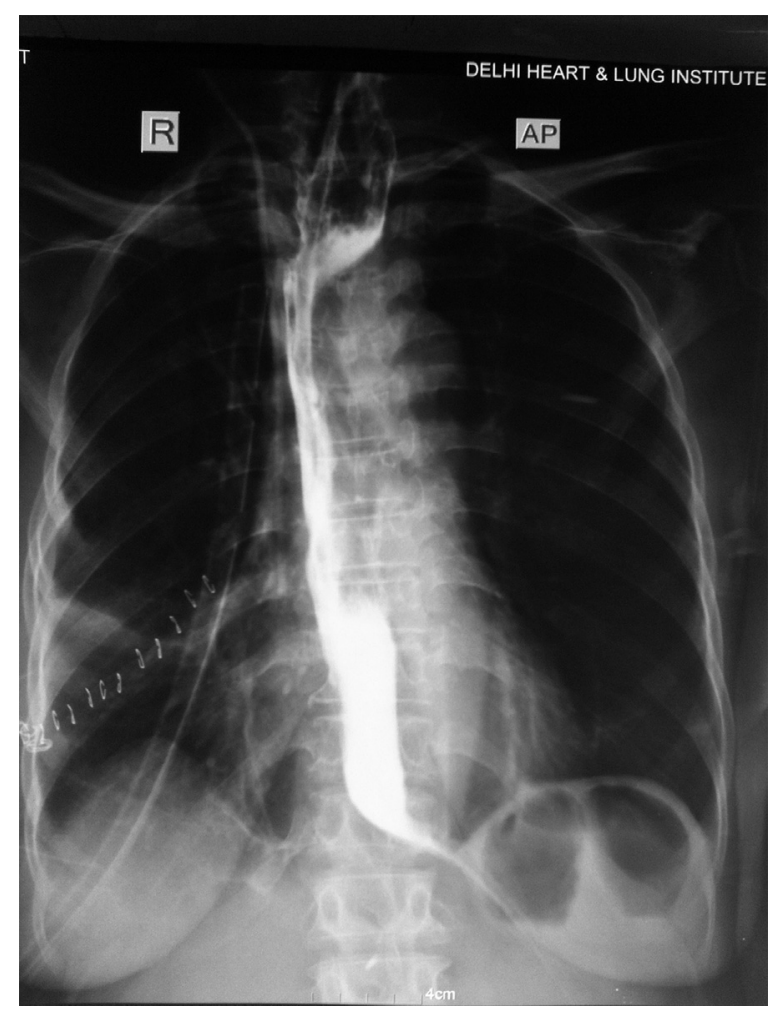

FIGURE 4. Gastrografin swallow.

curable condition. Even after removal of denture endoscopically, the role of conservative management for tracheoesophageal fistula is doubtful. ${ }^{2}$ In our opinion, TEF with in situ denture should undergo surgical intervention to remove the denture and repair the TEF (Video 1). Preoperative preparation should be done diligently to control pulmonary infection and ensure the patient has a good nutritional status. The presence of impacted denture in trachea may interfere with tracheal intubation. Our technique of mobilizing the denture and pushing it into fistula and esophagus facilitates tracheal intubation.

Single-stage primary repair of both airway and esophageal defect with tissue flap interposition can be performed safely with satisfactory results, ${ }^{5}$ as evident in this case. Adequate mobilization of trachea and esophagus, freshening the epithelized margin of rent in trachea and esophagus, and interposition of muscle or pleural flap are

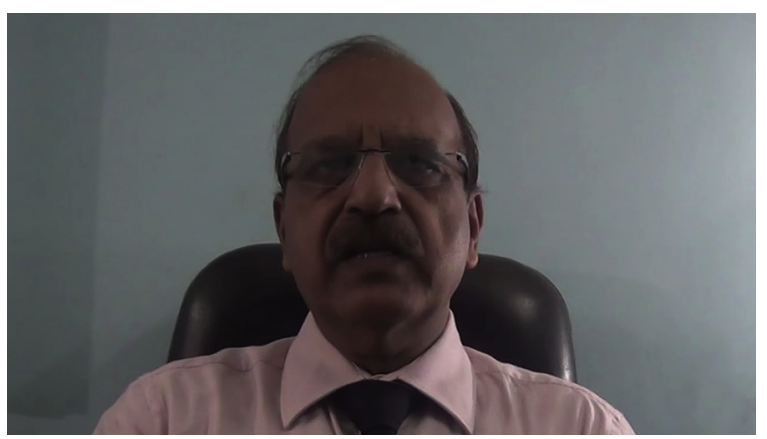

VIDEO 1. Video highlighting salient features of case, preoperative planning, operative steps, and postoperative management strategy. Video available at: http://www.jtcvsonline.org/article/S0022-5223(17)31163-7/ fulltext.

important operative steps to prevent reformation of TEF or tracheal and esophageal leak postoperatively. Although most authors interpose muscle, we chose a pedicled pleural flap because of its simplicity. Only ligating the fistulous communication may not succeed and result in reformation of TEF. Postoperative positive pressure ventilation is associated with an increased incidence of anastomotic breakdown and stenosis. ${ }^{6}$ Therefore, weaning and extubation should preferably be done in operating room itself before transferring the patient to intensive care unit, as we have done. Small frequent aliquots of oral normal saline help to flush viscid bacteria-laden saliva and prevent encrustation over the repair, preventing a nidus for infection and subsequent dehiscence.

\section{References}

1. Samarasam GI, Chandran S, Shukla V, Mathew G. A missing denture's misadventure! Dis Esophagus. 2006;19:53-5.

2. Gerzic Z, Rakic S, Randjelovic T. Acquired benign esophagorespiratory fistula: report of 16 consecutive cases. Ann Thorac Surg. 1990;50:724-7.

3. Darbari A, Suryavanshi A, Tandon S, Chandra G, Singh PK. Nonmalignant tracheo-esophageal fistula: our experience. Indian J Thorac Cardiovasc Surg. 2005;21:272-6.

4. Taha AS, Nakshabendi I, Russell RI. Vocal cord paralysis and oesophagobroncho-aortic fistula complicating foreign body-induced oesophageal perforation. Postgrad Med J. 1992;68:277-8.

5. Shen KR, Allen MS, Cassivi SD, Nichols FC III, Wigle DA, Harmsen WS, et al Surgical management of acquired nonmalignant tracheoesophageal and bronchoesophageal fistulae. Ann Thorac Surg. 2010;90:914-9.

6. Robins B, Das AK. Anesthetic management of acquired tracheoesophageal fistula: a brief report. Anesth Analg. 2001;93:903-5. 